Dalvan Antonio de Campos

Universidade Federal de Santa Catarina, Florianópolis, SC, Brasil

Rodrigo Otávio Moretti-Pires

Universidade Federal de Santa Catarina, Florianópolis, SC, Brasil

\title{
Trajetórias sociais de gays lésbicas moradores de rua de Florianópolis (SC), 2016
}

Resumo: Este artigo analisa os efeitos das relações de gênero nas trajetórias sociais de moradores de rua que se identificam como lésbicas e gays no município de Florianópolis/SC. A pesquisa foi desenvolvida em janeiro e fevereiro de 2016, com postura construcionista social. Realizaram-se entrevistas individuais e registros da observação participante com pessoas LGBT moradoras de rua. Os conflitos e violências familiares oriundos das fobias de gênero, balizadas pela heteronormatividade, apresentaram-se como principal estopim da ida de lésbicas e gays para a rua, todavia, aspectos socioeconômicos pregressos aparecem enquanto fatores determinantes para que a rua fosse o caminho escolhido. Apesar das violências constantes na rua, que extrapolam as fobias de gênero, as narrativas apontaram que o espaço atual se configura como um lugar melhor para seguirem suas vidas, quando comparado com os cenários anteriores.

Palovras-chave: moradores de rua, gay, lésbica, trajetória social, construcionismo social

\section{Introdução}

Na construção das cidades há distinção entre o espaço público e o privado. Os espaços públicos são organizados para receber as pessoas por um determinado tempo, ou seja, são locais de passagem, de lazer, de comércio e serviços. O ambiente privado é construído para guardar a intimidade, seja no âmbito doméstico ou do trabalho.

Nesse sentido, o espaço público e o privado não são espaços 'neutros' e dados em termos sociais/culturais. Do mesmo modo que acontece na arte, as formas dadas aos espaços públicos e privados são efeitos das construções sociais e relações de poder de um período

\section{(c) (7)}

Esta obra está sob licença Creative Commons. 
(Carla GUANAES-LORENZl et al., 2014, p. 30). Assim, há formas de expressão, comportamento, estilo, gestualidade, tipo de discurso que são privilegiadas em função do que é mais valorizado pelos grupos hegemônicos (Nancy FRASER, 1997, p. 56).

A discussão da construção, utilização e legitimação de discursos no espaço público e privado é central quando se trata da população de rua. Neste caso, há uma junção dos âmbitos público e privado, na medida em que o espaço público é também o privado e vice-versa. Assim, o cenário do morador de rua' é o espaço público, todavia, este lhe é negado, mais do que a qualquer outro cidadão. Dessa forma, mais do que viver nela, ele constrói novos sentidos para este cenário sobrevivendo aos desafios que a falta de previsibilidade e de constância impõe (Paula Rochlitz QUINTAO, 2012, p. 24).

A população de rua é compreendida como um grupo heterogêneo que possui em comum a pobreza extrema, os vínculos familiares interrompidos ou fragilizados e a inexistência de moradia convencional regular, utilizando logradouros públicos e áreas degradadas como espaço de moradia e de sustento, de forma temporária ou permanente, bem como as unidades de acolhimento para pernoite temporário ou como moradia provisória (BRASIL, 2009, p. 08). Ainda são restritos, no cenário nacional, estudos que abordem as relações de gênero e sexualidade com esta população.

Em uma perspectiva ampliada, a sexualidade é entendida como resultante de aspectos sociais, intelectuais e emocionais dos seres humanos, justificando o conceito de gênero. Esse é entendido como entidade não uniforme ao longo da história, variando entre diferentes sociedades, se constituindo em papéis sociais, modos de ser e agir desempenhados pelas pessoas conforme sua condição, determinados por relações de poder presentes no cerne da estrutura social. A identidade de gênero, portanto, está em constante construção tanto individual como nas relações sociais (Anthony GIDDENS, 2012, p. 115; Miriam Pillar GROSSI, 1998, p. 05; Judith BUTLER, 2003, p. 40).

Na sociedade ocidental, este padrão, uma norma, é retratado pela heteronormatividade, entendida como as instituições, estruturas de compreensão e orientações práticas que não apenas fazem com que a heterossexualidade pareça coerente - ou seja, organizada como sexualidade - mas também que seja privilegiada. Sua coerência é sempre provisional e seu privilégio pode adotar várias formas, às vezes contraditórias, passando despercebida como linguagem básica sobre aspectos sociais e pessoais, percebida como um estado natural que também se projeta como um objetivo ideal ou moral (Lauren BERLANT; Michael WARNER, 2002, p. 548).

Os efeitos das narrativas construídas a partir desse padrão resultam em violências e discriminações nas trajetórias da população LGBT, sendo que essas não diferem na forma, quando comparadas ao resto da população, mas sim no sentido, pois sua prática é justificada, de forma insensata, pela normalidade (Michael WARNER, 1993, p. 26). Os atos discriminatórios são oriundos do preconceito concretizado pela homofobia, que é o medo ou ódio com relação a lésbicas, gays, bissexuais, travestis, transexuais, fundamentado na percepção de que alguém vivencia uma orientação sexual não heterossexual (Jaqueline Gomes de JESUS, 2012, p. 29).

Destaca-se, mediante a intencionalidade deste manuscrito, que, no serviço de saúde, ambiente familiar, escolar e laboral tradicional e heteronormativo, os indivíduos que

\footnotetext{
1 Utilizaremos neste trabalho os termos moradora de rua, morador de rua e moradores de rua para nos referirmos às pessoas que residem nas ruas. Essa opção se dá pela crítica ao termo 'pessoa em situação de rua', que pode sugerir a interpretação de que estar na rua é, sempre, algo passageiro, temporário, provisório. Sabe-se que o processo de saída da rua, quando é opção da pessoa, é lento e gradual, principalmente porque depende de diversos fatores. Além disso, durante a pesquisa de campo as pessoas usavam o termo morador para referir-se a si mesmo e aos companheiros de rua.
} 
apresentam identidades de gênero 'dissidentes' geralmente sofrem repressão. Mediante este contexto de legitimação social das violências contra esta população, não são raros os casos de indivíduos que são expulsos de casa ou abandonam a casa da família por não seguirem o padrão heteronormativo (Roberto Vieira GARCIA, 2013, p. 1011).

Ao estudar a população LGBT moradora de rua deve-se considerar o conceito de exclusão, vinculado radicalmente às desigualdades sociais. Segundo Giddens (2012, p. 325), a exclusão social refere-se aos graus ou formas de afastamento de pessoas do pleno envolvimento na sociedade, pelos planos da socialização, economia e política.

Além disso, o estudo desta população, devido às características que promovem sua discriminação - como orientação sexual, raça, classe social -, exige um olhar a partir das interseccionalidades. Esse conceito sociológico propõe o estudo dos efeitos das intersecções e interações de identidades sociais relacionados à opressão na vida das pessoas, entre as diversas relações de poder (Kimberlé CRENSHAW, 2002, p. 174). Os efeitos desse processo complexo de exclusão das pessoas LGBT moradoras de rua podem ser percebidos também no desenvolvimento ainda ínfimo dos estudos com esta população no Brasil.

O primeiro estudo, em âmbito nacional, com esta população brasileira de rua foi realizado nos anos de 2007 e 2008, em todos os municípios com mais de 300 mil habitantes $(n=48)$, Distrito Federal e capitais dos estados $(n=22)$, exceto Belo Horizonte-MG, São Paulo$S P$, Recife-PE e Porto Alegre-RS, que já haviam realizado levantamentos recentes. $O$ quantitativo da população de rua, a partir dessas pesquisas, foi de cinquenta mil pessoas (BRASIL, 2008, p. 03). Após quase dez anos, em 2016, o Instituto de Pesquisa Econômica Aplicada (IPEA) realizou uma estimativa no país, sugerindo uma população de 101.854 pessoas nas ruas, ou seja, um crescimento de mais de $100 \%$ no período (Marco Antônio Carvalho NATALINO, 2016, p. 24).

Conforme "Pesquisa Nacional sobre a População em Situação de Rua" (BRASIL, 2008 , p. 07), os conflitos familiares correspondem a $29,1 \%$ das razões para as idas para a rua, ficando abaixo apenas do desemprego $(29,8 \%$ ) e alcoolismo/drogas $(35,5 \%)$. Entretanto, neste levantamento não foi questionado o motivo do conflito familiar e não houve questões que abordassem as relações de gênero, orientação sexual e identidade de gênero dos participantes.

Algumas pesquisas brasileiras trazem, de forma pontual, questões relativas à orientação sexual e gênero, demonstrando a presença constante de moradores de rua que se identificam como LGBT, assim como homens que fazem sexo com outros homens (Sarah ESCOREL, 1999, p. 65; Simone Miziara FRANGELLA, 2004, p. 131; Daniel de Lucca Reis COSTA, 2007, p. 218; Ercílio Neves Brandão LANGA, 2012, p. 35). Destaca-se, nesse sentido, o censo da população de rua realizado pela prefeitura de São Paulo no ano de 2015, em que cerca de $10 \%$ dos entrevistados se identificaram como LGBT (SÃO PAULO, 2015, p. 121).

Pesquisas realizadas no cenário internacional também identificaram a presença de pessoas LGBT entre a população de rua (Bryan COCHRAN et al., 2002, p. 774; Michael KENNEDY, 1991, p. 578; Jennifer UNGER et al., 1997, p. 381). Esta situação está relacionada à maior propensão dos jovens LGBT serem expulsos ou saírem de casa de forma precoce, devido ao preconceito, tendo, assim, que viver nas ruas ou em abrigos quando não possuem uma rede de apoio (Justeen HYDE, 2005, p. 176; Les WHITBECK et al., 2004, p. 330; Shelley MALLETT, 2009, p. 213).

Na literatura internacional também são descritas peculiaridades da população LGBT moradora de rua quando comparada com a que se identifica como heterossexual: maior frequência de violência (física e sexual) no ambiente familiar e na rua, após a saída de casa (WHITBECK et al., 2004, p. 340); maior vulnerabilidade ao uso de álcool e de drogas proibidas (COCHRAN et al., 2002, p. 774); maior discriminação no contexto da rua, 
tanto pelas outras pessoas moradoras de rua quanto pela polícia (Norweeta MILBURN et al., 2006, p. 663); maior número de parceiros sexuais (COCHRAN et al., 2002, p. 775); realização com maior frequência da troca de alimentos, drogas, abrigo e/ou dinheiro por atividade sexual, sendo mais propensos a ingresso na prostituição (WHITBECK et al., 2004, p. 330).

Corroborando esse estudo, os dados do censo da prefeitura de São Paulo apontam que a população de rua LGBT no município apresenta maior vulnerabilidade que os heterossexuais. Segundo a pesquisa, há mais pessoas LGBT exercendo a mendicância e atividades marginalizadas (prostituição, venda de drogas e roubo) quando comparadas com a população heterossexual. Além disso, há maior vulnerabilidade a acometimento por infecções sexualmente transmissíveis e tuberculose, como também ao uso de drogas proibidas (SÃO PAULO, 2015, p. 123).

Assim, mediante as peculiaridades apresentadas, compreender a trajetória dessas pessoas é importante para entender seus processos vivenciais, experiências e necessidades. Para isso, será utilizada neste artigo a postura construcionista social, uma forma de olhar o mundo, ou seja, uma postura filosófica que compreende que as realidades são construídas e pactuadas a partir das relações sociais em um determinado contexto cultural e histórico (Kenneth GERGEN; Mary GERGEN, 2010, p. 32).

Neste sentido, entende-se trajetórias sociais enquanto discursos construídos, formas de olhar que possibilitam a compreensão de narrativas e construção de sentidos (GERGEN; GERGEN, 2010, p. 26). Elas são contrárias ao conceito de biografia, no que Pierre BOURDIEU (1996, p. 71) chama de ilusão biográfica. As trajetórias podem ser compreendidas como uma maneira singular de percorrer e construir as narrativas no espaço onde se exprimem as disposições do habitus, ${ }^{2}$ ou seja, que determinados deslocamentos ou sentidos implicam a exclusão de outras possibilidades de construir e narrar as trajetórias. Sendo assim, ela é única, entretanto situacional (BOURDIEU, 1996, p. 71).

Visto isso, o presente artigo objetivou analisar os efeitos das relações de gênero nas trajetórias sociais de pessoas moradoras de rua que se identificaram como lésbicas e gays no município de Florianópolis/SC.

\section{Percurso metodológico}

Este é um estudo qualitativo, ou seja, um conjunto de práticas que engloba os sentidos atribuídos pelos indivíduos às experiências, vivências e aos contextos relacionais onde estão inseridas (Maria Lucia Magalhães BOSI; Francisco Javier MERCADO, 2007, p. 105). A abordagem é construída a partir de uma postura construcionista social enquanto suporte epistemológico e metodológico (GERGEN; GERGEN, 2010, p. 30; GUANAES-LORENZI et al., 2014, p. 25) entendendo que os discursos são expressos de formas diferentes dependendo do contexto em que os indivíduos estão inseridos, do local em que se situam, com quem falam, do que lhe foi dito anteriormente e da interação estabelecida (Mary Jane SPINK, 2010, p. 15).

${ }^{2}$ O habitus é um conceito importante na construção teórica de Pierre Bourdieu (1983) referente às relações entre agentes e estruturas, em um processo de mútua coprodução. A despeito da aparência de estabilidade o habitus está em constante construção e reconstrução, tanto em termos de comportamentos e crenças aprendidos quanto dos mecanismos de suas reproduções. Conforme Pierre Bourdieu, são "sistemas de disposições duráveis e transponíveis, estruturas estruturadas predispostas a funcionar como estruturas estruturantes, isto é, como princípios geradores e organizadores de práticas e de representações que podem ser objetivamente adaptadas a seu fim sem supor a percepção consciente dos fins e o domínio expresso das operações necessárias para os atingir; objetivamente 'regrados' e 'regulares' sem ser de forma alguma o produto da obediência a regras, e, sendo assim, coletivamente orquestrados sem ser o produto da ação organizadora de um maestro" (p. 65).

4 Revista Estudos Feministas, Florianópolis, 26(2): e45995 
A pesquisa foi desenvolvida nos meses de janeiro e fevereiro de 2016, nas ruas do bairro Centro, do município de Florianópolis, capital do estado de Santa Catarina, região Sul do Brasil. A estimativa é de que, em 2008, a capital catarinense possuía 426 moradores de rua (BRASIL, 2008, p. 15), sendo que não há informações oficiais atualizadas da população de rua da cidade, nem levantamento que possibilite o conhecimento da população LGBT moradora de rua. A população de rua de Florianópolis concentra-se na região central do município, no bairro Centro e arredores, em que se localiza grande parte dos comércios e serviços, com grande fluxo de pessoas durante o dia. Além disso, nessa região, estão as principais instituições de apoio para esta população (Deidvid ABREU, 2013, p. 92).

Mediante a configuração do campo de pesquisa, para levantamento das informações e seleção dos interlocutores para as entrevistas, foi adotada uma postura etnográfica, ou, como sugerido na postura construcionista, observação no cotidiano, em que o pesquisador participa e interfere no contexto investigado, com ênfase na análise das ações no cotidiano e não do cotidiano, para o desenvolvimento do estudo (Seiji ARAGAKI et al., 2014, p. 60). Deste modo, frequentou-se diariamente e em diferentes horários os espaços em que os moradores de rua se concentram, inicialmente com $o$ intuito de adentrar 0 campo, considerando a dificuldade de acesso aos diálogos e vivências compartilhadas e, posteriormente, com o intuito de manter e reforçar os vínculos para aprofundar os diálogos.

Para registro das informações provenientes da observação no cotidiano foi utilizado o diário de campo. Neste foram registradas as percepções sobre os espaços, ações, expressões, também insights, inquietações, dúvidas, angústias e sentimentos provenientes da interação, além de partes de relatos expostos durante as conversas informais (Milagros Garcia CARDONA; Rosineide Meira CORDEIRO; Jullyane BRASILINO, 2014, p. 124).

Após a entrada no campo, em que o pesquisador passou a frequentar os espaços e as relações dos moradores de rua, também foi realizada a coleta de informações por meio de entrevistas individuais abertas (Maria Cecilia de Souza MINAYO, 2007, p. 129). Para tanto, foram convidados moradores de rua que possuíam a experiência e a vivência relacionadas ao que se desejava estudar (Michael Quinn PATTON, 1990, p. 181). Ou seja, moradores de rua LGBT que tivessem como motivo da saída de casa os problemas familiares. Não foram inseridas na pesquisa pessoas com idade inferior a dezoito anos ou com deficiência mental que impossibilitasse a entrevista.

Os cenários das conversas e entrevistas foram diversos, entretanto, em geral, foram as calçadas, bancos e marquises. As entrevistas foram realizadas de forma dialogada e os entrevistados foram convidados a contar sua trajetória social. Como forma de direcionar a conversa, foram utilizados os seguintes tópicos: motivos que o levaram para rua; processo da saída de casa e fixação na rua; motivos que o mantêm na rua; efeitos da expressão de gênero nas relações no contexto da rua (entre os moradores de rua, com os não moradores de rua e com as instituições de apoio).

A opção pela entrevista individual se justificou pelo interesse em aprofundar a conversa em determinadas trajetórias. Neste trabalho, todavia, esta ferramenta não é entendida como apetrecho para coleta de informações pré-existentes, mas sim de coconstrução de discursos na interação entre pesquisador e participantes no momento das entrevistas (ARAGAKI et al., 2014, p. 60). As entrevistas foram gravadas e, após as coletas, transcritas na íntegra para posterior análise.

A análise foi realizada por meio de imersão do pesquisador nas informações coletadas. A descrição das trajetórias foi balizada pelos tópicos utilizados na condução das entrevistas. O pesquisador refletiu acerca dos sentidos construídos pelos moradores de rua, debatendo, para tanto, com a literatura de gênero (SPINK; Helena LIMA, 2004, p. 98). 
O presente estudo foi submetido e aprovado, sob o protocolo $n^{\circ} 104963 / 2015$, pelo Comitê de Ética em Pesquisa com Seres Humanos da Universidade Federal de Santa Catarina, conforme a Resolução CNS 466/12.

\section{Resultados e discussão}

Durante a imersão nas ruas do centro de Florianópolis nos dois meses de contato constante com este cenário, foram realizadas conversas com diversos moradores de rua. Neste processo dialógico foram construídos significados sobre suas vidas e trajetórias, o que os convidou a pensar, reconstruir e falar sobre suas vidas e experiências.

Nesse sentido, colocar em diálogo constante as teorias, os registros das observações e conversas possibilitou a desconstrução de estigmas e estereótipos, passando a entender alguns processos sociais que os compõem, o que Langa (2012, p. 17) denomina habitus da rua. Esse habitus não se trata de uma estrutura, ou estruturas unidirecionais, moldes que constroem moradores de rua, mas sim características sociais compartilhadas que, ao mesmo tempo em que constroem, são construídas por esses agentes em seus dia a dias.

Alguns contatos e conversas se desenrolaram de forma fragmentada, com intervenções dispersas e fora do contexto, apresentando contradições explícitas ao direcionamento dos assuntos. Elas foram influenciadas pelo desconhecimento inicial e condições físicas, psicológicas e emocionais dos interlocutores alteradas pelas vivências na rua, provocando um afastamento compreensível. Entretanto, com o tempo, as conversas foram se aprofundando e ficando fluentes, lúcidas e com detalhamento de acontecimentos recentes e dos primeiros anos de rua e de vida. Foram abordados os mais variados assuntos, como a relação com a família, religião, valores pessoais, sexualidade, orientação sexual, trabalho, estudos, relações afetivas entre outras. O material analisado permite olhares diversos para sua exploração e significação no campo científico, sendo que a opção feita foi a de usar a lente dos discursos sobre gênero e sexualidade.

Devido ao formato escolhido para a construção deste manuscrito, que solicita um grande volume de informações acerca das trajetórias sociais dos interlocutores, foram utilizadas quatro entrevistas com narrativas de moradores de rua gays e lésbicas que tinham como motivo de saída de casa conflitos familiares. Além disso, é importante destacar que essas pessoas tiveram contato constante com o pesquisador de forma a permitir uma maior interação, o que possibilitou diálogos mais aprofundados e um detalhamento maior das narrativas.

Conforme explicitado, registrar essas histórias ${ }^{3}$ contadas e recontadas pelos interlocutores não objetiva recriar uma biografia de suas vidas, todavia, estes elementos narrados pelo pesquisador acerca dos discursos coconstruídos durante a pesquisa de campo visam ao auxílio na reflexão de como as relações de gênero estão implicadas em trajetórias de pessoas LGBT que se encontram na rua atualmente (BOURDIEU, 1996, p. 71). Para apresentar as trajetórias dos moradores de rua, conforme pactuado com eles, foram usados codinomes (São José, Pomerode, Mineiro, Porto Alegre) referentes aos locais de moradia pregressos ou nascimento deles.

\footnotetext{
${ }^{3}$ Em uma postura construcionista social radical não há sentido em se empregarem as falas das pessoas moradoras de rua já que a construção textual é um ato discursivo das pessoas que operam a tessitura do texto, e especialmente não se intenciona registrar uma realidade estável e/ou essencial. A construção textual é o final de um processo de coconstrução durante as vivências e entrevistas, mas assumidamente um exercício circunscrito ao mundo acadêmico. Na medida da seleção de falas, tal como usada em outras perspectivas teórico-metodológicas, questiona-se a aparência de verdade que as mesmas produzem, mas que, em caráter final, trata-se de um resultado de opções das pessoas autoras dos textos, e não da realidade empírica, até porque mesmo essa não é essencial, mas sim discursiva, contextual e contingente.
} 
A primeira trajetória é da São José, nascida no município de São José, cidade da Grande Florianópolis. Tem vinte e seis anos, sexo feminino, identifica-se como sapatão/ lésbica, mas prefere a primeira denominação, é homossexual e negra. Constrói seu corpo e performance social com características masculinas, usa um 'top' que lhe aperta os seios, como um binder ${ }^{4}$ improvisado, parecendo que não os possui. Tem cabelos curtos, olhos pretos, é magra, baixa e está sempre com roupas largas, camiseta regata, bermuda jeans e tênis esportivo. Como quase todos os moradores de rua, relata que usa frequentemente as mesmas vestes, exceto quando consegue alguma peça nova. Seus gestos e postura são viris e afirma que enfrenta qualquer um com palavrões, empurrões e, se necessário, parte pra luta corporal. Ela domina seu 'pedaço'!

O controle dos 'pedaços', espaços em que há convivência de pessoas que pactuam das mesmas regras (José Guilherme Cantor MAGNANI, 1998, p. 44), implica uma relação de monitoramento constante dos acontecimentos e forma de agir das pessoas que os compõem, mesmo que de forma não perceptível. Sendo assim, há uma vigilância hierárquica que se ramifica nas normas de regulação desses espaços, tendo efeito direto na performance dos moradores de rua.

As relações de poder e resistência emergem das condições sociais e estruturais presentes na rua, sendo que a ausência das leis formais permite a configuração de outras regras. O domínio do 'pedaço', assim como a prescrição da ordem, é determinado por corpos moldados, com características viris, independente da narrativa biológica dada ao corpo, sendo a expressão de gênero fundamental nessa relação (Michel FOUCAULT, 2014, p. 8).

Ela conta que desde os cinco até os dezoito anos alternou a moradia entre a casa de familiares, em um bairro carente do município de São José, e um abrigo para crianças e adolescentes em Florianópolis, devido à morte de sua mãe, ocorrida quando tinha quatro anos, que, por alguns anos, também morou na rua. Lembra que passou a se relacionar com outras mulheres durante o período em que esteve presa por tráfico de drogas. Após a reclusão voltou para a casa de sua avó, todavia, esta não aceitava suas relações com outras mulheres e o consumo de drogas, que aumentaram após as vivências no presídio. Como não teve apoio de amigos e conhecidos e já tinha atingido a maioridade, impeditivo para voltar ao abrigo, decidiu morar nas ruas de Florianópolis, pois não queria incomodar sua família. Afirma que está há quatro anos na rua, sendo que mantém contato pontual com familiares e com pessoas que conheceu no período em que esteve no abrigo.

O processo que leva à desfiliação das pessoas que passam a morar nas ruas parece ser balizado por uma série de fatores sociais, econômicos e culturais que, mediante as narrativas construídas nos contextos em que vivem, influenciam as suas trajetórias (ESCOREL, 1999, p. 62). A ida para rua não é um processo simples, pois implica a carência de outras possibilidades, seja de acesso a recursos materiais ou a capital social (Pierre BOURDIEU, 2001, p. 68; Camila GIORGETTI, 2014, p. 67). Estar na rua é também efeito de desigualdades sociais e de outras exclusões pregressas que permitem que esta seja a possibilidade escolhida.

O consumo abusivo de drogas permitidas e proibidas e problemas de ordem mental muitas vezes inviabilizam o convívio com os familiares e são destacados na literatura (Jaime Alonso CARAVACA-MORERA; Maria Itayra PADILHA, 2015, p. 751), todavia, há um silenciamento no que tange aos efeitos das relações de gênero entre as pessoas que moram nas ruas, principalmente na literatura brasileira.

\footnotetext{
${ }^{4}$ Veste feita com tecido elástico fechado com velcro ou zíper utilizado na região peitoral com o intuito de moldar os seios de forma que não fiquem proeminentes.
} 
Neste aspecto, observa-se que as desigualdades e violências de gênero estão intimamente relacionadas com os conflitos familiares motivadores da ida para a rua, principalmente quando tratamos das pessoas LGBT moradoras de rua. Essas vivenciam constantemente os discursos que operam as fobias de gênero na sociedade, logo, nas instituições como escola e família (BOURDIEU, 1998, p. 23; JESUS, 2012, p. 29).

Segundo Michael Kennedy (1991, p. 576), a população de adolescentes LGBT moradores de rua é composta majoritariamente por pessoas que tiveram divergências familiares em relação à identidade de gênero. Ser gay, lésbica ou bissexual foi motivo de desentendimentos, sendo que o perfil socioeconômico das famílias não se apresentou como proteção para a não saída de casa, visło que o perfil dessa população é heterogêneo naquele contexto. No caso da São José, esse conflito de perspectivas no interior da família se deu após a adolescência, pois estava no abrigo durante este período. Neste sentido, há de se considerar que os aspectos sociais e econômicos pregressos influenciaram na trajetória dela de ida para a rua.

A São José relata que, desde que saiu de casa, morou nas ruas de Florianópolis, mas pretende conhecer o Rio de Janeiro com seu amigo de marquise Ceará, que já rodou alguns lugares do Brasil morando na rua. Referiu ter relações afetivas e sexuais com algumas companheiras de rua, mas espera sua companheira de prisão sair para ficarem juntas. Tanto nas ruas quanto no período anterior, afirma trabalhar na venda de drogas. Nas ruas, cuida de carros e mangueira quando necessita. Apesar das dificuldades cotidianas, como os conflitos com moradores de rua e não moradores, além das atitudes preconceituosas que vivencia, diz que tem a rua como um espaço em que se sente mais livre para expressar sua identidade de gênero ('ser sapatão') e consumir drogas, sendo que não pretende voltar para a casa dos familiares.

A relação dos moradores de rua com as drogas permitidas e proibidas é constante, visto que uma parte da população faz uso de delas (LANGA, 2012, p. 38). O acesso a essas substâncias, geralmente nas comunidades carentes de Florianópolis, exige certa cautela e conhecimento pregresso. Nesse sentido, a compra das drogas nas 'bocas' é feita por determinados moradores de rua. Geralmente os homens fazem o levantamento de dinheiro nos 'pedaços', compram as drogas e cobram uma taxa, paga em droga. Entretanto, a performance masculina de São José e, principalmente, sua vivência pregressa com o tráfico, faz com que ela tenha acesso às 'bocas' e faça o repasse, diferente das outras mulheres e gays.

A segunda trajetória é de Porto Alegre, nascida em São Leopoldo, cidade da Grande Porto Alegre, em família de classe média. Tem vinte e sete anos, sexo feminino e se identifica como lésbica, homossexual e branca. Constrói seu corpo e performance a partir de características femininas, tem fala e atitudes reservadas. Possui olhos castanhos, quase sempre olhando para o chão, longos cabelos castanhos, geralmente amarrados, pele clara, mas escurecida pelo sol e pela vida na rua. O corpo emagrecido sustenta uma calça jeans, camiseta azul, sem estampa, e nos pés sujos, chinelos gastos pelas longas distâncias que percorre para conseguir e vender os reciclados. Apesar disso, é cobiçada pelos moradores de rua, mesmo os que sabem de sua orientação sexual. Esses, além da cobiça, fazem 'piadas' com isso.

A possibilidade de construir uma existência homossexual para as mulheres na rua exige resistência constante, isso porque, na rua, a presença predominante de homens que se identificam como heterossexuais faz com que os corpos que possuem vagina sejam muito cobiçados (Priscilla Ribeiro BISCOTTO et al., 2016, p. 754). Além disso, são perceptíveis discursos que operam na lógica machista, objetificando o corpo feminino e entendendo o papel da mulher como de servidora do homem. Nesse sentido, as mulheres lésbicas na rua, 
principalmente quando não têm performance masculina, são convidadas a ocupar um espaço em que sua identidade e orientação sexual não importam, ou, mais do que isso, está 'equivocada' mediante sua 'natureza' (BUTLER, 2003, p. 40).

Porto Alegre relatou também que sempre soube de sua atração afetiva por mulheres, entretanto, pelos discursos conservadores de sua família, manteve isso em segredo e até tentou relacionamentos com homens na adolescência. Quando se formou no ensino médio, com dezoito anos, decidiu conversar com os pais sobre sua sexualidade e deparou-se com uma intolerância que não esperava. Como resultado, foi estuprada por seu pai e tio, dias após a conversa, com o discurso de que aprenderia a gostar de homens. Mediante a situação, fugiu de casa e da cidade para tentar uma vida nova em Porto Alegre.

O cenário familiar da população LGBT se mostra imerso em narrativas de violência, legitimadas e naturalizadas no habitus heteronormativo (Marcelo VIEIRA, 2015, p. 67). No tocante da trajetória de Porto Alegre, a população lésbica vivencia o chamado estupro 'corretivo' que, com a justificativa, inconsequente, de mostrar à mulher como ser mulher, ou melhor, como ser mulher nos moldes da heteronormatividade e para servir ao homem, submete mulheres lésbicas a relações sexuais forçadas com homens, geralmente familiares (WARNER, 1993, p. 548; Tatiana Nascimento SANTOS; Bruna Pinheiro ARAUJO; Luiza Rocha RABELLO, 2014, p. 117).

Segundo Whitbeck et al. (2004, p. 340), em estudo com sessenta e três pessoas LGBT e 366 heterossexuais moradoras de rua no meio oeste dos EUA, a população LGBT está submetida à maior frequência de violência (física e sexual) no ambiente familiar e na rua, após a saída de casa. No estudo, identificou-se que $51,2 \%$ das jovens lésbicas moradoras de rua já sofreram abuso sexual, porcentagem muito superior quando comparada às mulheres heterossexuais $(32,7 \%)$ e homens gays $(27,8 \%)$ observados no estudo.

Embora com dificuldade, Porto Alegre continuou a contar sua trajetória, dizendo que após a chegada à nova cidade conseguiu emprego em uma rede de supermercados. Trabalhou por algum tempo e conseguia pagar um quarto para morar, mas o que ganhava garantia apenas o pagamento do espaço e comida. Nesse período sua família a procurou várias vezes e conseguiu contato, mas ela se manteve resistente ao retorno. Ao ser dispensada do emprego, decidiu ir para Florianópolis, com o intuito de impedir o contato da família, que Ihe trazia péssimas recordações, e recomeçar uma nova vida. Com o dinheiro que conseguiu da rescisão comprou uma passagem, pegou seus pertences e partiu. Quando chegou, buscou emprego formal por cerca de três meses, tempo em que conseguiu pagar um quarto com seus rendimentos. Sem sucesso, foi dormir nas ruas da cidade e trabalhar com reciclados. Está a sete anos na rua e desde então não tem mais contato com familiares e amigos antigos.

A intersecção entre as violências de gênero, a quebra de vínculos familiares, os movimentos de migração e mudanças de classe social devem ser observadas, visto que a pobreza está manifesta e se manifesta de forma desigual entre os grupos populacionais, a depender de outros fatores excludentes (Lucas Paoli ITABORAHY, 2014, p. 23). Deste modo, percebe-se a estreita relação entre identidade de gênero e classe social, pois, mesmo tendo origem em uma família de classe média, os efeitos da exposição da identidade lésbica motivaram, para Porto Alegre, um declínio de classe social e quebra de capital social, culminando na troca de estado e ida para a rua.

Nas ruas, ela passou a usar drogas, principalmente para se manter acordada durante as noites, com medo da violência, para 'amortecer seus sentimentos', e muitas vezes fez uso de grandes quantidades para 'apagar' e conseguir dormir. Referiu ter dormido só e acordado acompanhada várias vezes, principalmente no início de sua vida na rua. Além disso, sofre assédio constante dos homens moradores de rua, todavia, com o tempo, foi conhecendo os 
colegas de rua e os lugares seguros para dormir. Desde que começou a residir nas ruas, trabalha com reciclagem, principalmente de papelão e lata. Consegue comprar alimentos, produtos de higiene pessoal e drogas com os rendimentos, entretanto, conta com ajuda para conseguir roupas, apesar de referir com orgulho que já conseguiu comprar algumas com dinheiro próprio. Ela afirma que a rua não se configura como o lar ideal para ela; pensa em sair assim que puder, entretanto, apesar das dificuldades, refere estar feliz com os caminhos que percorreu até o momento.

No imaginário social, as trajetórias dos moradores geralmente se vinculam em algum momento com o uso de drogas, relacionando o uso como motivador da ida para a rua. Entretanto, segundo a "Pesquisa Nacional sobre a População em Situação de Rua" (BRASIL, 2008, p. 07), nem todos os moradores fazem uso de drogas e o uso é motivo principal da ida para as ruas em apenas $35,5 \%$ da população, demonstrando que, assim como fora das ruas, o uso de drogas é presente, mas não totalizante. Nota-se que ignorar o consumo de drogas na rua seria inconsequente, entretanto, estigmatizar esta população pelo uso, sem entender os motivos pelos quais ele é feito, seria inconsequente e prejudicial para uma aproximação e ações com estas pessoas (Ulrich BECK, 201 1, p. 234).

Em relação ao consumo de drogas pelas pessoas LGBT moradoras de rua, Cochran et al. (2002, p. 775) e Whitbeck et al. (2004, p. 335) apontam que, nos EUA, quando comparadas com a população heterossexual, as pessoas LGBT apresentam maior frequência de consumo de álcool e drogas proibidas. Os autores relacionaram o consumo aumentado com a exposição pregressa à violência sexual e física. Conforme a trajetória de Porto Alegre, é possível perceber que, no contexto investigado, para as mulheres lésbicas, o uso está relacionado com a sensação de insegurança de viver nas ruas, comum a toda a população de rua, todavia, agravada no caso dos corpos femininos que, construídos a partir de discursos machistas, ocupam a posição de fragilidade e domínio masculino, justificando, de forma insensata, sua violação (BOURDIEU, 1998, p. 38).

A terceira trajetória é de Pomerode, nascido no vale do Rio ltajaí, na cidade de Pomerode. Tem trinta anos, sexo masculino, identifica-se como 'viado' e gay, homossexual e branco. Cabelos curtos, louros, olhos azuis, tem pele avermelhada e surrada pelo sol, os pés sujos. Calça um chinelo velho, com a ponta dos dedos pretos e corroídos. Traja roupas justas e tem performance com características femininas, inclusive a entonação da voz.

Alega ser filho caçula, de quatro irmãos de agricultores, muito religiosos e conservadores de um distrito rural da cidade e que ainda na escola começou a se sentir atraído por outros meninos, todavia, nunca soube como conversar sobre isso com a família. Tanto a família quanto as pessoas da comunidade sabiam que era gay, um constante motivo de chacota e agressões no decorrer de sua infância e adolescência. Após anos de convivência com as violências, mesmo nunca tendo se relacionado com outros homens, decidiu, com vinte anos, conversar com os pais sobre o sofrimento que passava escondendo sua orientação sexual e pedir apoio para morar em outra cidade. Como resultado de sua conversa, disse que ouviu do pai que ele não o considerava mais como filho e que daquele dia pra frente não poderia mais entrar na casa deles. A mãe tentou mediar, mas foi agredida pelo pai. Ele ainda voltou a conversar com o pai e buscou ajuda dos irmãos, mas todos foram irredutíveis. Sendo assim, juntou o que conseguiu em uma mochila, pegou alguns trocados de um esconderijo de seus pais e, no mesmo dia da conversa, partiu para Blumenau. Referiu que ficou perdido, pois nunca havia saído de sua cidade, mas, com o passar do tempo, foi conhecendo os moradores de rua e os lugares daquele novo lar. Passou pouco mais de um ano em Blumenau, mas por convite de seu primeiro namorado, também morador de rua, foi para Florianópolis. Relatou que desde sua conversa com os pais, há 10 anos, nunca mais teve contato com seus familiares. 
Na população de rua é possível perceber uma grande parte de pessoas provenientes dos interiores do Brasil. Em geral, os deslocamentos são feitos em busca de melhores oportunidades de vida, no sentido econômico (NATALINO, 2016, p.19). Entretanto, para além de questões econômicas, as cidades pequenas ou com baixa densidade populacional marcam a vida das pessoas LGBT, pois nesses espaços o vínculo social construído entre os habitantes é próximo, todos se conhecem. Além disso, os costumes conservadores, vinculados aos ensinamentos das religiões, exacerbam as relações pautadas em discursos machistas e heteronormativos (Rodrigo Otávio MORETTI-PIRES et al., 2016, p. 101).

No caso de Pomerode, ser gay fez com que perdesse sua rede familiar e social, visto que, pela configuração de sua cidade, não era bem quisto pelos conterrâneos. Existir nesses lugares enquanto pessoa LGBT é um grande desafio e muitas vezes essa existência só é possível após a saída de casa ou, ainda, da cidade (Fernando Silva TEIXEIRA-FILHO; Carina Alexandra RONDONI; Juliana Cristina BESSA, 201 1, p. 735). Os efeitos, no caso dele, foram a ida para a rua e a situação de pobreza extrema.

A trajetória de saída de casa, na maioria dos casos, transcorre com garantia de suporte, seja dos pais, familiares ou rede social. Em geral, as pessoas vão estudar em universidades ou trabalhar em outras cidades ou estados (VIEIRA, 2015, p. 48). Nesse sentido, deve-se considerar os aspectos sociais e econômicos pregressos, que irão influenciar diretamente nas possibilidades e impossibilidades após a saída de casa. Na trajetória apresentada, as relações sociais interioranas, pautadas em uma lógica heteronormativa, potencializaram a desfiliação abrupta e sem suporte, tornando a rua o caminho possível.

A quarta trajetória é de Mineiro, nascido em Belo Horizonte, Minas Gerais. Tem trinta e dois anos, sexo masculino, se identifica como gay, homossexual e negro. Tem olhos pretos, sorriso largo, mas com poucos dentes, e os que têm estão muito comprometidos. É discreto, com performance masculina, fala pouco, mas adora contar suas histórias. Em uma delas, referiu ter sido 'mal nascido', pois é filho de mãe solteira, de família pobre e de periferia, criado pelos tios, pois sua mãe lhe abandonou quando tinha dois anos. Relatou que o contato com as drogas, assim como a autopercepção enquanto gay, ocorreram ainda na pré-adolescência, sendo que quando compartilhou com seus tios sua identidade de gênero foi entendido como louco e doente. Com o objetivo de curá-lo, levaram-no à igreja e até em uma curandeira da comunidade.

Apesar de ser amplamente discutida e mesmo após serem criados mecanismos legais que orientam ao não uso nem propagação da ideia de que a condição homossexual necessite de tratamento, a 'cura' gay parece permanecer nos discursos heteronormativos de forma irredutível, o que deveras é preocupante. Essa narrativa de cura, ou seja, de uma 'ajuda', geralmente sobrepõe e mascara atitudes fóbicas em relação à possibilidade de uma diversidade sexual e de gênero (MORETI-PIRES et al., 2016, p. 102).

Nesse sentido, percebe-se um hábito contemporâneo de patologizar condições e comportamentos, ressalta-se a necessidade de um olhar atento quando se busca diagnósticos ou, mesmo, características tratáveis para as pessoas que moram nas ruas. Nas duas situações, parece nada mais que uma forma cômoda de não olhar para as diversas construções e relações de poder da sociedade que possibilitam ou impossibilitam determinadas vivências (Sandra Elena SPOSITO, 2012, p. 101; FOUCAULT, 2014, p. 09).

Segundo Mineiro, nada teve o efeito esperado pela família, e em certo ponto por ele, pois chegou a acreditar que tinha problemas de ordem mental. Conta que se sentia péssimo pela situação a que era submetido, mas ao ter contato com outros gays na adolescência passou a se aceitar melhor e não mais conversou sobre isso com os familiares, levando uma vida secreta por algum tempo. Todavia, relatou que, em uma saída da escola, foi surpreendido por seu tio enquanto estava beijando o namorado. Esta situação motivou a 
tentativa de homicídio, com golpes de faca quando ele chegou em casa. Ao relatar isso, me mostrou as cicatrizes na região das costelas e disse ter sido salvo por uma vizinha que entrou na casa gritando, segurou o tio e levou-o para o hospital. Relembra que o episódio aconteceu quando ele tinha em torno de dezesseis anos e que teve acompanhamento do conselho tutelar no hospital, mas antes de receber alta fugiu pelo medo que sentia.

Os diversos tipos de violências fazem parte do cotidiano da população LGBT, entretanto, percebe-se uma diferença na forma como essa é praticada. Enquanto nas mulheres lésbicas o estupro 'corretivo' é a forma de manifestar a violência, nos homens gays, a violência física, com atentado à vida, é mais comum (Murilo dos Santos MOSCHETA; Daniele da Silva FÉBOLE; Bárbara ANZOLIN, 2016, p. 73). Conforme Silvia RAMOS e Sérgio CARRARA (2006, p. 194), ao analisar casos de homicídios envolvendo homossexuais, percebe-se que há um senso e processo de impunidade dos homicídios, quando se trata de homossexuais. Assim, fica evidente a justificativa social para ações desenvolvidas, a partir de racionalidades fóbicas, nos corpos que se identificam como lésbica ou gay.

Desde então Mineiro vive nas ruas, inicialmente em Belo Horizonte, passando por São Paulo e Porto Alegre. Está há seis anos em Florianópolis. Considera que as ruas da atual cidade, apesar de violentas e frias no inverno, são mais brandas que a dos outros lugares em que já esteve. Atribui isso à relação entre os moradores de rua que, apesar de agressiva, não apresenta tanta agressão física quanto em outros lugares, assim como as ações da polícia, que são menos ostensivas em Florianópolis. Entretanto, afirma ter sido 'mal tratado' e alvo de preconceito, tanto por colegas de rua quanto por pessoas que não moram na rua, que sabem ou desconfiam que ele se identifica como gay.

Nesse sentido, podemos significar essas diferenças a partir da própria racionalidade da dominação masculina, pois se os corpos com vagina são entendidos como frágeis e devem servir aos desejos masculinos, serão convidados a ocupar o lugar da submissão, serão assediados e, se necessário, forçados a fazer o que o lugar que lhes é atribuído solicita, mesmo que de forma punitiva, visando a um 'ajuste' ao que a norma sugere (BOURDIEU, 1998, p. 29).

Por outro lado, os corpos com pênis, que nesta lógica deveriam ocupar o espaço da virilidade e domínio em relação às mulheres, e, principalmente, na provação aos outros homens, ao não apresentarem esta performance para manutenção do status quo, serão convidados a ocupar o lugar do 'traidor', justificando, mediante esta lógica, um convite ao 'ajuste' por meio da punição severa, sendo o homicídio uma narrativa possível (BOURDIEU, 1998, p. 29).

Percebe-se que cada uma das trajetórias apresenta suas peculiaridades, seja pelos motivos apresentados para a saída de casa, seja pelos efeitos dessa saída e vivências nas ruas. Entretanto, a violência no âmbito familiar, produto dos conflitos oriundos da não aceitação da identidade de gênero, apareceu de modo transversal nas narrativas de gays e lésbicas moradores de rua. Além disso, a busca pela cura da homossexualidade, mesmo que com formas diferentes, foi comum a gays e lésbicas.

A influência das condições econômicas e sociais precárias, pregressas à saída de casa, apareceu como fator determinante para que a rua fosse o local possível para estas pessoas. Assim como o uso de drogas, que apareceu enquanto um motivador de ida, mas também como um fator de adaptação às vivências na ruas e manutenção nelas.

No contexto da rua, a cobiça dos corpos femininos apresentou uma relação diferente, quando comparadas as performances masculinizada e feminizada. A primeira apresentase enquanto proteção para os assédios, seja pelo receio da agressão proveniente da mulher, seja por não chamar atenção dos homens. Já a segunda apresenta-se enquanto risco para assédios e incitação de violência sexual, atribuídos à suposta fragilidade e racionalidade de dominação masculina desses corpos.

12 Revista Estudos Feministas, Florianópolis, 26(2): e45995 
As diferenças do tipo de violência entre gays e lésbicas são relevantes, se analisadas a partir da perspectiva de gênero. As violências, em casa e nas ruas, cometidas contra as lésbicas, vinculam-se à sua condição mulher, repercutindo em assédio e violência sexual. Os gays apresentam violências físicas e menosprezo por serem homossexuais. Ambos os efeitos buscam ajustar corpos e performances a partir de uma racionalidade de dominação masculina e heterocentrada. Apesar da continuidade das violências na rua, cabe salientar que eles percebem a rua enquanto um lugar melhor para seguir suas vidas que a casa dos familiares.

\section{Considerações finais}

As fobias de gênero, balizadas pela heteronormatividade, apresentaram-se como principal estopim para os conflitos familiares que precederam a ida para a rua das lésbicas e gays moradores de rua. Todavia, nota-se que as violências, experiências e possibilidades apresentam-se de forma singular em cada uma das trajetórias, o que convida a um cuidado com discursos generalizantes sobre a temática.

Percebe-se que, entre as pessoas LGBT moradoras de rua, as desigualdades sociais pregressas, principalmente econômicas e de capital social, são fator determinante para a ida às ruas e exclusão social. Apesar do contexto de exclusão social nas ruas, nas trajetórias analisadas, elas aparecem enquanto espaço de opção, mediante as vivências pregressas, principalmente no âmbito familiar.

Quando comparados com a população LGBT não moradora de rua, os LGBT moradores de rua, apesar de sofrerem pelo mesmo discurso social que justifica as violências, apresentam uma situação de dupla exclusão, ou seja, além das violações causadas por serem LGBT, somam a condição de moradores. Isso nos convida a questionar as desigualdades internas presentes em grupos vulneráveis, como a população LGBT.

Deste modo, percebe-se a necessidade de ações voltadas para jovens LGBT em situação de vulnerabilidade para evitar que a rua se torne a melhor opção em contextos violentos, visto os efeitos da vida na rua. Também há necessidade de ampliação de estudos com moradores de rua LGBT para que se conheça melhor as especificidades dessa população para o desenvolvimento de ações específicas. E, em um plano mais amplo, nota-se a necessidade da busca pela ampliação das discussões sobre gênero e sexualidade, desconstruindo a racionalidade machista e heteronormativa que produz efeitos violentos na vida das pessoas.

\section{Referências}

ABREU, Deidvid. Pessoas em situação de rua, uso de drogas e o consultório de rua. 2013. Dissertação (Mestrado em Saúde Coletiva) - Programa de Pós-Graduação em Saúde Coletiva, Universidade Federal de Santa Catarina, Florianópolis, SC, Brasil.

ARAGAKI, Seiji et al. "Entrevistas: negociando sentidos e coproduzindo versões de realidade". In: SPINK, Mary Jane et al. (Orgs.). A produção de informação na pesquisa social: compartilhando ferramentas. Rio de Janeiro: Centro Edelstein de Pesquisas Sociais, 2014. p. 57-72.

BECK, Ulrich. Sociedade de risco: rumo a uma outra modernidade. São Paulo: Editora 34, 2011.

BERLANT, Lauren; WARNER, Michael. "Sexo em Público". In: JIMÉNEZ, Rafael (Org.). Sexualidades transgressoras. Barcelona: Içaria, 2002. p. 547-566.

BISCOTTO, Priscilla Ribeiro et al. "Compreensão da vivência de mulheres em situação de rua". Revista da Escola de Enfermagem USP, Ribeirão Preto, v. 50, n. 5, p. 749-755, 2016. 
BOSI, Maria Lucia Magalhães; MERCADO, Francisco Javier. Pesquisa qualitativa de serviços de saúde. Petrópolis: Vozes, 2007.

BOURDIEU, Pierre. Sociologia. São Paulo: Ática, 1983.

BOURDIEU, Pierre. Razões práticas: sobre a teoria da ação. São Paulo: Papirus Editora, 1996.

BOURDIEU, Pierre. A dominação masculina. Rio de Janeiro: Bestbolso, 1998.

BOURDIEU, Pierre. "O capital social: notas provisórias". In: NOGUEIRA, Maria Alice; CATANI, Afrânio (Orgs.). Escritos de Educação. Petrópolis: Vozes, 2001 . p. 67-69.

BRASIL. Pesquisa Nacional sobre a População em Situação de Rua. Brasília: Ministério do Desenvolvimento Social e Combate à Fome, 2008.

BRASIL. Política Nacional para inclusão Social da População em situação de Rua. Brasília: Ministério do Desenvolvimento Social e Combate à Fome, 2009.

BUTLER, Judith. Problemas de gênero: feminismo e subversão da identidade. Rio de Janeiro: Civilização Brasileira, 2003. p. 40.

CARAVACA-MORERA, Jaime Alonso; PADILHA, Maria ltayra. "A dinâmica das relações familiares de moradores de rua usuários de crack". Saúde em debate, Rio de Janeiro, v. 39, n. 106, p. 748-759, 2015.

CARDONA, Milagros Garcia; CORDEIRO, Rosineide Meira; BRASILINO, Jullyane. "Observação no cotidiano: um modo de fazer pesquisa em psicologia social". In: SPINK, Mary Jane et al. (Orgs). A produção de informação na pesquisa social: compartilhando ferramentas. Rio de Janeiro: Centro Edelstein de Pesquisas Sociais, 2014. p. 123-148.

COCHRAN, Bryan et al. "Challenges faced by homeless sexual minorities: Comparison of gay, lesbian, bisexual, and transgender homeless adolescents with their heterosexual counterparts". American Journal of Public Health, Washington DC, v. 92, n. 5, p. 773777, 2002.

COSTA, Daniel de Lucca Reis. A rua em movimento: experiências urbanas e jogos sociais em torno da população de rua. 2007. Dissertação (Mestrado em Antropologia Social) Faculdade de Filosofia, Letras e Ciências Humanas, Universidade de São Paulo, São Paulo, SP, Brasil.

CRENSHAW, Kimberlé. "Documento para o encontro de especialistas em aspectos da discriminação racial relativos ao gênero". Revista Estudos Feministas, Florianópolis, v. 10, n. 1, p. 171-188, 2002.

ESCOREL, Sarah. Vidas ao léu: trajetórias de exclusão social. Rio de Janeiro: Fiocruz, 1999.

FOUCAULT, Michel. Microfísica do poder. São Paulo: Paz \& Terra, 2014.

FRANGELLA, Simone Miziara. Corpos urbanos errantes: uma etnografia da corporalidade de moradores de uma rua em São Paulo. 2004. Tese (Doutorado em Antropologia) Instituto de Filosofia e Ciências Humanas, Universidade Estadual de Campinas (UNICAMP), Campinas, SP, Brasil.

FRASER, Nancy. Justice interruptus: Critical reflections on the "postsocialist" condition. London: Cambridge University Press, 1997.

GARCIA, Roberto Vieira. "Diversidade sexual, situação de rua, vivências nômades e contextos de vulnerabilidade ao HIV/AIDS". Temas em Psicologia, Ribeirão Preto, v. 21 , n. 3, p. $1011,2013$.

GERGEN, Kenneth; GERGEN, Mary. Construcionismo social: um convite ao diálogo. Rio de Janeiro: Instituto NOOS, 2010.

GIDDENS, Anthony. Sociologia. Porto Alegre: Penso, 2012.

GIORGETTI, Camila. Moradores de rua: Uma questão social? São Paulo: FAPESP, 2014.

GROSSI, Miriam Pillar. Identidade de gênero e sexualidade, 1998, p. 05. Disponível em: $\mathrm{h} t \mathrm{tp}$ : //bibliobase.sermais.pt: 8008 / BiblionET/upload/PDF 3 / 01935 identidade_genero_revisado.pdf. Acesso em: 10/07/2016.

14 Revista Estudos Feministas, Florianópolis, 26(2): e45995 
GUANAES-LORENZI, Carla et al. Construcionismo social: discurso, prática e produção do conhecimento. Rio de Janeiro: Instituto NOOS, 2014.

HYDE, Justeen. "From home to street: Understanding young people's transitions into homelessness". Journal of Adolescence, Amsterdam, v. 28, n. 2, p. 171-183, 2005.

ITABORAHY, Lucas Paoli. Pessoas LGBT vivendo em pobreza no Rio de Janeiro. Londres: Micro Rainbow International CIC, 2014.

JESUS, Jaqueline Gomes de. Orientações sobre identidade de gênero: conceitos e termos, 2012, p. 29. Disponível em: http://www.diversidadesexual.com.br/wp-content/uploads/ 2013/04/GÊNERO-CONCEITOS-E-TERMOS.pdf. Acesso em: 26/09/2016.

KENNEDY, Michael. "Homeless and runaway youth mental health issues: no access to the system". Journal of Adolescent Health, Philadelphia, v. 12, n. 7, p. 576-579, 1991.

LANGA, Ercílio Neves Brandão. Pessoas que habitam as ruas em Fortaleza nos circuitos da vulnerabilidade e exclusão: identidades em construção nas trajetórias e percursos. 2012. Dissertação (Mestrado em Sociologia) - Programa de Pós-Graduação em Sociologia, Universidade Federal do Ceará, Fortaleza, CE, Brasil.

MAGNANI, José Guilherme Cantor. Festa no pedaço: cultura popular e lazer na cidade. São Paulo: Hucitec, 1998.

MALLETT, Shelley. Moving out, moving on: young people's pathways in and through homelessness. Abingdon: Taylor \& Francis, 2009.

MILBURN, Norweeta et al. "Discrimination and exiting homelessness among homeless adolescents". Cultural Diversity and Ethnic Minority Psychology, Washington DC, v. 12 , n. 4, p. 658-672, 2006.

MINAYO, Maria Cecilia de Souza. O desafio do conhecimento: Pesquisa Qualitativa em Saúde. São Paulo: Hucitec, 2007.

MORETTI-PIRES, Rodrigo Otávio et al. "Pastores, ovelhas desgarradas e as disputas pelo rebanho: Sobre a transcrucificação na Parada do orgulho LGBT de São Paulo em 2015". Revista Crítica de Ciências Sociais, Coimbra, n. 110, p. 99-116, 2016.

MOSCHETA, Murilo dos Santos; FÉBOLE, Daniele da Silva; ANZOLIN, Bárbara. "Visibilidade seletiva: a influência da heterossexualidade compulsória nos cuidados em saúde de homens gays e mulheres lésbicas e bissexuais". Saúde \& Transformação Social, Florianópolis, v. 7, n. 3, p. 71-83, 2016.

NATALINO, Marco Antônio Carvalho. Estimativa da População em Situação de Rua no Brasil. Rio de Janeiro: IPEA, 2016.

PATTON, Michael Quinn. Qualitative evaluation and research methods. Beverly Hills: SAGE Publications, 1990.

QUINTAO, Paula Rochlitz. Morar na rua: há projeto possível? 2012. Dissertação (Mestrado em Arquitetura e Urbanismo) - Faculdade de Arquitetura e Urbanismo, Universidade de São Paulo, São Paulo, SP, Brasil.

RAMOS, Silvia; CARRARA, Sérgio. "A Constituição da Problemática da Violência contra Homossexuais: a articulação entre ativismo e academia na elaboração de Políticas Públicas". Physis: Revista de Saúde Coletiva, Rio de Janeiro, v. 16, n. 2, p. 185-205, 2006.

SANTOS, Tatiana Nascimento; ARAUJO, Bruna Pinheiro; RABELLO, Luiza Rocha. "Percepções de lésbicas e não lésbicas sobre a possibilidade de aplicação da Lei Maria da Penha em casos de lesbofobia intrafamiliar e doméstica". Bagoas, Natal, v. 2, n. 11 , p. 101 $119,2014$.

SÃO PAULO. Pesquisa Censitária da População em Situação de Rua: Caracterização Socioeconômica da População Adulta em Situação de Rua e Relatório Temático de Identificação das Necessidades desta População na Cidade de São Paulo. São Paulo: FIPE, 2015. 
SPINK, Mary Jane. Linguagem e produção de sentidos no cotidiano. Rio de Janeiro: BVCE, 2010.

SPINK, Mary Jane; LIMA, Helena. "Rigor e visibilidade: a explicitação dos passos da interpretação". In: SPINK, Mary Jane. Práticas discursivas e produção de sentidos no cotidiano: aproximações teóricas e metodológicas. São Paulo: Cortez, 2004. p. 93-122.

SPOSITO, Sandra Elena. "Psicologia, Sexualidade e Religiapo: Ligac'opes Perigosas". Revista de Psicologia da Unesp, São Paulo, v. 1, n. 11, p.100-104, 2012.

TEIXEIRA-FILHO, Fernando Silva; RONDINI, Carina Alexandra; BESSA, Juliana Cristina. "Reflexões sobre homofobia e educação em escolas do interior paulista". Educação e Pesquisa, São Paulo, v. 37, n. 4, p.725-741, 2011.

UNGER, Jennifer et al. "Homeless youths and young adults in Los Angeles: Prevalence of mental health problems and the relationship between mental health and substance abuse disorders". American Journal of Community Psychology, v. 25, n. 3, p. 371-394, 1997.

VIEIRA, Marcelo. "Quero poder existir": contornos da violência simbólica contra orientações sexuais não binárias entre universitários LGBT da Universidade Federal de Santa Catarina. 2015. Dissertação (Mestrado em Saúde Coletiva) - Programa de Pós-Graduação em Saúde Coletiva, Universidade Federal de Santa Catarina, Florianópolis, SC, Brasil.

WARNER, Michael. Fear of a queer planet: Queer politics and social theory. Minnesota: University of Minnesota Press, 1993. p. 26.

WHITBECK, Les et al. "Mental disorder, subsistence strategies, and victimization among gay, lesbian, and bisexual homeless and runaway adolescents". Journal of Sex Research, Abingdon, v. 41 , n. 4, p. 329-342, 2004.

[Recebido em 02/08/2016,

reapresentado em $24 / 11 / 2017$ e aprovado em 21/12/2017]

Social Trajectories of Homeless Gays and Lesbians in Florianopolis (SC), 2016

Abstract: This study analyzes the effects of gender relations on the social trajectories of homeless people who identify themselves as lesbian and gay in the city of Florianopolis/SC. The research was developed in the months of January and February of 2016, with social constructionist posture. Individual interviews and records from the participant observation were conducted with homeless LGBT. Conflicts and family violence stemming from gender phobias, marked by heteronormativity, were the main reason for lesbian and gay going to street. However, previous socioeconomic aspects appear as determining factors for the street to be chosen. Despite the constant violence on the street, for reasons that go beyond gender identity, all the narratives pointed out that the current space is a better place to follow their lives when compared to the previous scenarios. Keywords: Homeless; Gay; Lesbian; Social Trajectory; Social Constructionism

Dalvan Antonio de Campos (dalvandecampos@gmail.com) é doutorando do Programa de Pós-Graduação em Saúde Coletiva da Universidade Federal de Santa Catarina.

Rodrigo Otávio Moretti-Pires (rodrigo.moretti@ufsc.br) é sociólogo e pertence ao Departamento de Saúde Pública da Universidade Federal de Santa Catarina. 